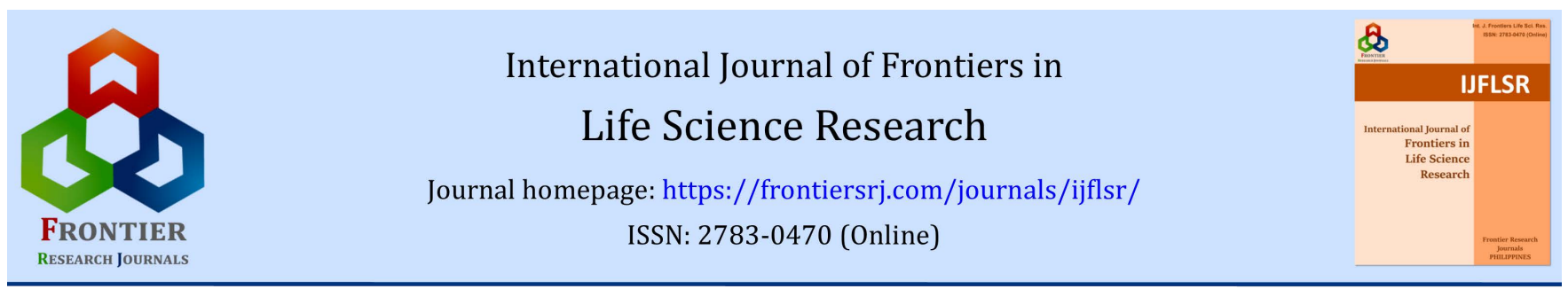

(RESEARCH ARTICLE)

Check for updates

\title{
Identification of morphometric variation of Aegel marmelos (L.) Correa correlated with habitat types in Western Terai
}

\author{
Bimal Bahadur Kunwar* \\ Faculty of Environmental Management, Prince of Songkla University, Hatyai, Thailand \\ International Journal of Frontiers in Life Science Research, 2021, 01(01), 001-017 \\ Publication history: Received on 04 March 2021; revised on 10 April 2021; accepted on 14 April 2021
}

Article DOI: https://doi.org/10.53294/ijflsr.2021.1.1.0031

\begin{abstract}
Aegle marmelos (L.) Correa locally called "Bael" is an economically important plant mainly harvested and traded for medicinal as well as religious purposes. Most of the collection of the plant is from forest. Due to habitat change, deforestation and over harvesting, it is feared that such important plant and its precious genetic diversity may be lost from the nature. Responding to these challenges a major initiative has been launched in the Western Terai Landscape Complex of Nepal to identify morphometric variability in A. marmelos.

Morphometric characters variation of this species in Western Terai Landscape Complex was statically and numerically evaluated. Sixteen populations were analysed, using 27 morphological characters of leaves and fruit, collected during 2007/2008 naturally. Most of the morphological characters were not significant with the east-west longitudinal gradient except few were, probably because of small gradient. The variation in the $A$. marmelos is clearly verified by uniand multivariate statistics. Highest variation was observed in the (DL) Disc Level (CV=6.08) from different morphometric characters and later that in PL and B. These DL, PL and B were determining characters of morphometric variation. Similarly, principal component and cluster analysis through forming dendrogram of morphometric traits indicated different grouping pattern of populations. The populations that are nearer to each other are not cluster together. At different sites of sampling analysis of variance in the morphometric traits revealed remarkable variation among population.
\end{abstract}

Keywords: Variability; Phenotype; Longitudinal Gradient; Statistical; Significant

\section{Introduction}

Plant diversity has fascinated humankind throughout history, primarily due to the tremendous variation that exists in nature for morphological and other development traits. Comparable development that exists in within many species (intraspecific), which likely reflects adaptations to different natural environments and it is the origin of plant species differentiation [1]. Individual within a species of plant is typically differing in morphology over a geographic range. Although some of this variation may be random, ecological theory posits that a large proportion of this variation may be representing adaptive matching of morphotypes to a variable environment [2]. Variation in size, shape, coloration, behaviour and physiology may be a product of current environmental differences between sites (phenotypic plasticity), a product of heritable (genotype differences) between the sub populations at different sites, or a combination of both. Phenotypic variation is the important pattern of variation to develop superior population stands. Plant developmental traits, defined merely as the morphological and colour feature that are determined by cell division, expansion and differentiation throughout the plant life cycle, include an enormous set of variable traits. When different natural genotypes of the same species are directly compared, heritable variation is observed for the number, size, shape,

\footnotetext{
${ }^{*}$ Corresponding author: Bimal Bahadur Kunwar

Faculty of Environmental Management, Prince of Songkla University, Hatyai, Thailand.

Copyright (C) 2021 Author(s) retain the copyright of this article. This article is published under the terms of the Creative Commons Attribution Liscense 4.0.
} 
distribution or colour of particular cell types. Large variation is also detected for the size, shape, number, organization and colour pattern of the basic plant organs (roots, leaves and stems) and of some complex structures (flowers, fruits and seeds) [3].

There may be considerable difference between population, between plants of the same population growing in different sites or even between plants of a single population growing together. The characteristics of the growing plant, taken altogether are known as the phenotypic. The individual plant is open to much more environmentally induced variation over a much greater part of its life so greater morphometric variability of plant is more than in higher animals. It is caused by the persistent of meristem or region of undifferentiated growing tissue in plant. If the differences are largely genetic rather than environmental, the variation is usually specified as racial, ecotypical or cline.

Two major processes promote the differentiation of geographical races into new species: random and genetic drift and natural selection [1]. When genetic drift is the main mechanism, such a relationship between phenotypic similarities and geographical character have been investigated along various gradient, such as latitude/longitude [4], [5]., climate[6], rainfall [7], soil and nutrient [8], [9]. Genetic variability of species is necessary for the productivity and to adapt to shifting ecological conditions. It is, therefore itself a natural resource and is necessary to give attention towards the management of the renewable genetic resources for their continuous supply of goods and services. The knowledge about the genetic diversity should help to identify what to emphasize in conservation and management efforts. It is always desirable to know that species are the most appropriate or commercially valuable for a particular site and there are a number of trials established for comparing species. However, the global awakening of interest in the genetic management of forest tree population has not been witnessed yet in Nepal.

Variations in the important traits are very significant for domestication and their management that is helpful for the conservation of plant species in natural habitats. The variation is differences in form or function between individuals. Population or species that may or may not be heritable and offers possibilities for improvement of adaptation sites and production requirements. It integrates peoples and plant, relationship and help in the maintenance of biological diversities. It is therefore, necessary to determine the amount, nature and cause of economic importance of variation present in the plant species. The purpose of this study was, therefore, to identification of morphometric variation on $A$. marmelos in the studied area which are rich and unique in genetic diversity (sink areas) and complementary habitats to further enrich it (source areas). The study had set a hypothesis; there are no significant differences in morphometric characters of $A$. marmelos along with longitudinal gradient i.e. $\mathrm{H}_{0}=\mu 1 \neq \mu 2$.

The distribution of the family Rutaceae Rue/Citrus (Latin for rue) is worldwide especially in the tropical regions, including 153 genera and 1800 species. The Rutaceae is characterized by development of oil glands producing aromatic oil [10]. Aegle belongs to one of the monotypic genera of sub family Rosidae, tribe clauseneae and sub tribe Balsamocitrinae. It has a single species Aegle marmelos but other related which are purposed but were not written are A. barteri, A. correa, A. decandra, A. glutinosa, A. sepiaria.

The Aegle marmelos (L.) Correa (Syns. Feronia pellucid Roth., Cratevaeva marmelos L.) is also called Bengal quince, Bael fruit, Indian quince, golden apple, holy fruit, stone apple; bel, bela (Nepali, Hindi); Sirphal, Malur, Amritfal, Mahafal, Sadafal, Willow (Sanskrit); Bel, Marmelos (Trade name) and other dialectal names are Ohshit, Opesheet in Burmese; Phneou or Pnoi in Cambodian; Oranger du Malabar in French; Maja, Maja batuh in Indonesian; Modjo in Java; Torum in Lao (Sino-Tibetan); Bilak or Maja pahit in Malayan; Marmelos in Portuguese; Matum, Mapin and Tum in Thailand; Mbau nau, Trai mam in Vietnamese.

A. Marmelos is indigenous to dry forests on hills and plains of central and southern India, southern Nepal, Sri Lanka, Myanmar, Pakistan, Bangladesh, also in mixed deciduous forests of former French Indochina: Vietnam, Laos, Cambodia and Thailand. It is cultivated throughout India, as well as in Sri Lanka, northern Malay Peninsula, and Java and to a limited extent on northern Luzon in the Philippines Islands. It is grown in some Egyptian gardens, and in Surinam and Trinidad. The tree is a subtropical species. It grows up to $1200 \mathrm{~m}$ where the temperature rises to $48.89{ }^{\circ} \mathrm{C}$ in the shade in summer and descends to $-6.67{ }^{\circ} \mathrm{C}$ in the winter, under prolonged drought. It will not fruit where there is no long dry season, as in southern Malaya. Warm/Humid climate and sunny situation favour the higher yield. The A. marmelos fruit is said to be best on rich, well-drained soil, but it has grown well and fruited on the oolitic limestone of southern Florida. It grows luxuriantly in swampy alkaline or sandy loam soils with sufficient moisture and in the soils having $\mathrm{pH}$ range from 5-10. In Nepal, the plant is found from east to west up to the altitude of $1220 \mathrm{~m}$ [11],[12],[13],[14]. 


\subsection{Taxonomic description of the species}

A. marmelos is deciduous medium sized an erect tree with few and irregular branches; about $10 \mathrm{~m}$ tall, grows on open places. Bark ash-coloured with furrows, strong, very sharp, axillary thorns, single or in pairs. Leaves are odd pinnate, alternate, leaflets trifoliate rarely pantafoliate, ovate-lanceolate, gland dotted, lateral sub-sessile or terminal long petioled, crenate, obtuse. Flower is greenish-white, bisexual, in short panicles, sweet scented; sepals 5, lobed, deciduous; petals 5, gland dotted, numerous, oblong much longer than sepals; many stamens, filaments short and anther narrow, basifixed; ovary bright green with an inconspicuous disc. Fruit is about $6 \mathrm{~cm}$ in diameter (of about the size of a large orange), globular, ovoid or pyriform, greyish or yellowish-brown, has a faint aromatic odour and mucilaginous taste, with a hard smooth shell. Rind about three millimetres in diameters, and adherent to a pale-reddish juicy pulp in which are ten to fifteen cells, each containing several woolly seeds a large quantity of exceedingly tenacious mucilage, which when dried is hard and transparent. Flowering period is April to June; soon after the new leaves appear and the fruit ripens in 10 to 11 months from bloom March to June of the following year.

\subsection{Economic Importance}

Plant diversity has fascinated humankind throughout history. Medicinal plants have been used to cure a number of diseases. There is a widespread belief that green medicines are healthier and more harmless or safer than synthetic ones. Apparently, A. marmelos tree is well known and respected all over the world for its healing properties but mainly in the East by Natives as precious source of food and drink, to build or make tools and things to use in the daily life in a house and for rituals.

The Hindu who expires under the A. marmelos tree expect to obtain immediate salvation. Fruits and leaves are used during Fulpati of Dashain, the Hindus greatest festival. Wood is used in the special religious ceremony. Marrying Newar maidan, with Bael fruit is still practice in Nepal. It is official in both the Pharmacopoeia of India and the British Pharmacopoeia. Juice of root, about 3 teaspoonful twice a day is given for fever; wood ash mixed with some water is spread over swollen part of the body, especially when someone has fever [15]. The juice of root is given to treat fever; sugar candy is added on the juice of its root, mixed with rice, and given to child suffering from diarrohea and stomach pain [12]. Root bark is used in intermittent fever and is useful in hypochondriasis, melancholia and palpitation of heart; it is astringent, cooling, carmitive, restorative, laxative, febrifuge, stomachic; uses for colitis, colic dysentery, diarrhoea, flatulence, fever and vomiting [13]. The leaves are expectorant, astringent, digestive, febrifuge and laxative and also useful in diabetes, ophthalmic and asthmatic complaints [15], [16]. The fruit has a delicious flavour and pleasant odour when ripe. The ripe fruit is astringent, aromatic, cooling, febrifuge, laxative and tonic to the heart and brain [17]. Pulp of ripe fruit is eaten fresh or mixed with cold water to prepare the juice, Sarbat during the hot summer season, which is much esteemed as laxative; dried fruit freed of pulp are used as cups, also for storing snuff [15]. Stem and around seed yield gum and that gummy substances serves as an adhesive, also used as varnish for picture and add brilliancy to water colour paints [18]. The leaves cause abortion and sterility in women; the bark is used as a fish poison in the Celebes; tannin, ingested frequently and in quantity over a long period, is antinutrient and carcinogenic [19].

\subsection{Study area}

The research was carried out at Western Terai Landscape Complex of Nepal which comprises three districts namely, Kanchanpur, Kailali and Bardia districts that extends from $28^{\circ} 59^{\prime} 13^{\prime \prime}, 80^{\circ} 06^{\prime} 05^{\prime \prime}$ and $28^{\circ} 04^{\prime} 14^{\prime \prime}-81^{\circ} 30^{\prime} 07^{\prime \prime}$ (Figure 1, a). The area lies in Terai Duar Savana Grassland ecoregion, one of WWF's global 200 ecoregions, covering a total area of 3466 sq. km. of Terai Arc Landscape [20]. Topographically the area have two distinct zones: the lowland Terai in the south (which was this case study area) and Churia hills in the North. For the conservation and sustainable use of globally significant biodiversity in Nepal's Western Terai Landscape Complex and establish effective management systems and building capacity of community, local organizations and line agencies, the Ministry of Forests and Soil Conservation (MFSC) implemented the Western Terai Landscape Complex Project (WTLCP). The research utilizes local knowledge with scientific studies such as taxonomic surveys, ecological studies to formulate a sound conservation strategy for the establishment of Rauvolfia serpentina plant Gene Bank and its management in WTLC areas of Nepal. The area occupied by forest is $2069 \mathrm{~km}^{2}$ (59.7\%), cultivated land $1102 \mathrm{~km}^{2}(31.8 \%)$ and others $295 \mathrm{~km}^{2}$ (8.5\%). Shorea robusta forest, tropical deciduous riverine forest, tropical evergreen forest, Terminalia forest, Dalbergia sisoo-Acacia catechu forest, Pinus roxburghii forest and subtropical deciduous Hill forest are the types of forest decorate and enrich the area. More than $80 \%$ of the people in this area are involved in agriculture. Bardia National Park (968 km²) with Buffer Zone $(237$ $\left.\mathrm{km}^{2}\right)$ and Shuklaphanta Wildlife Reserve $\left(305 \mathrm{~km}^{2}\right)$ with Buffer zone $\left(153 \mathrm{~km}^{2}\right)$ are the protected areas of this territory. Dry and hot climate is found in the region. Thirteen climatic stations are found within the area. Maximum and minimum temperatures, rainfall and relative humidity at evening and morning is shown in Figure 1 (b). Altogether, 16 places of Western Terai, Nepal have been surveyed during the course of study. 


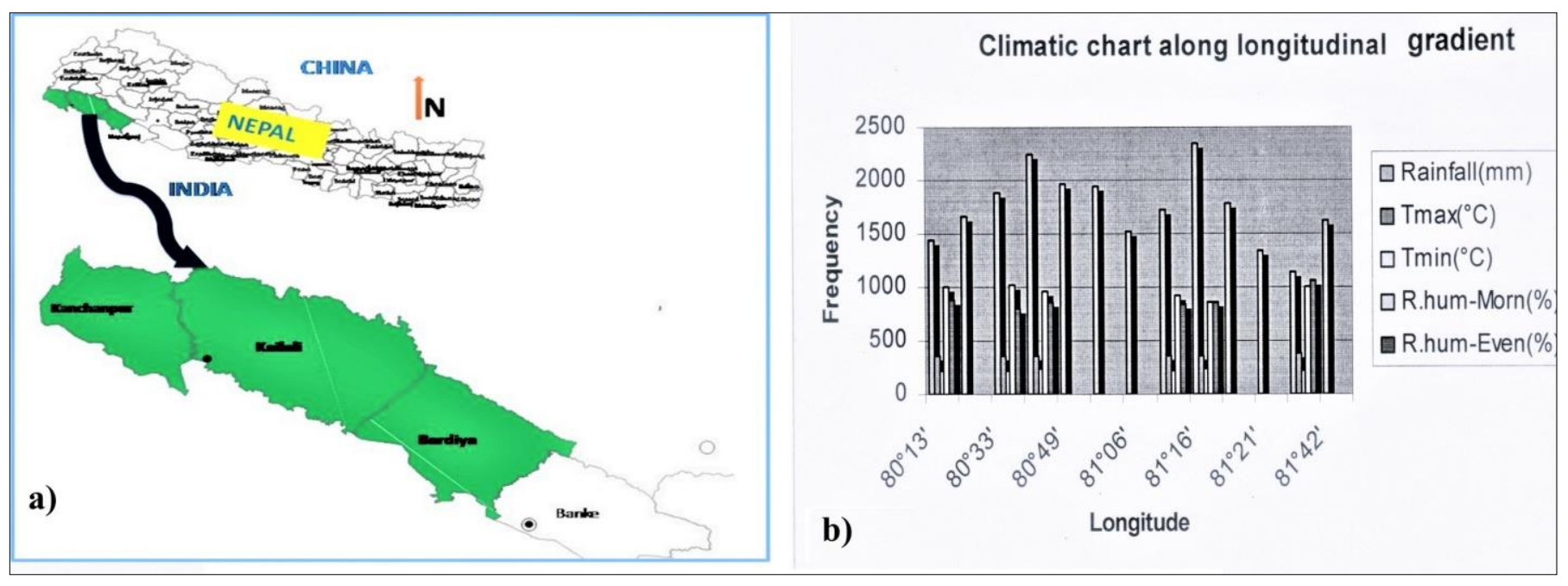

Figure 1 a) Study area, b) Climatic data of the study area (2003-2007) along longitude. (Source Department of Hydrology and Climate, Babar mahal, Kathmandu).

\section{Material and methods}

\subsection{Sample collection}

The focus of the study was on the mapping morphometric diversity of the species. Samples were collected from different place of the study area where they were found. To give an estimate representing the special means five well developed leaves and fruits were sampled from randomly selected trees. The sampled were collected from different branches around the tree, to give a representative sample. On very large specimens, leaves and fruits were taken from one branch. Only mature specimens old enough to fruiting were sampled to reduce variation caused by age differences.

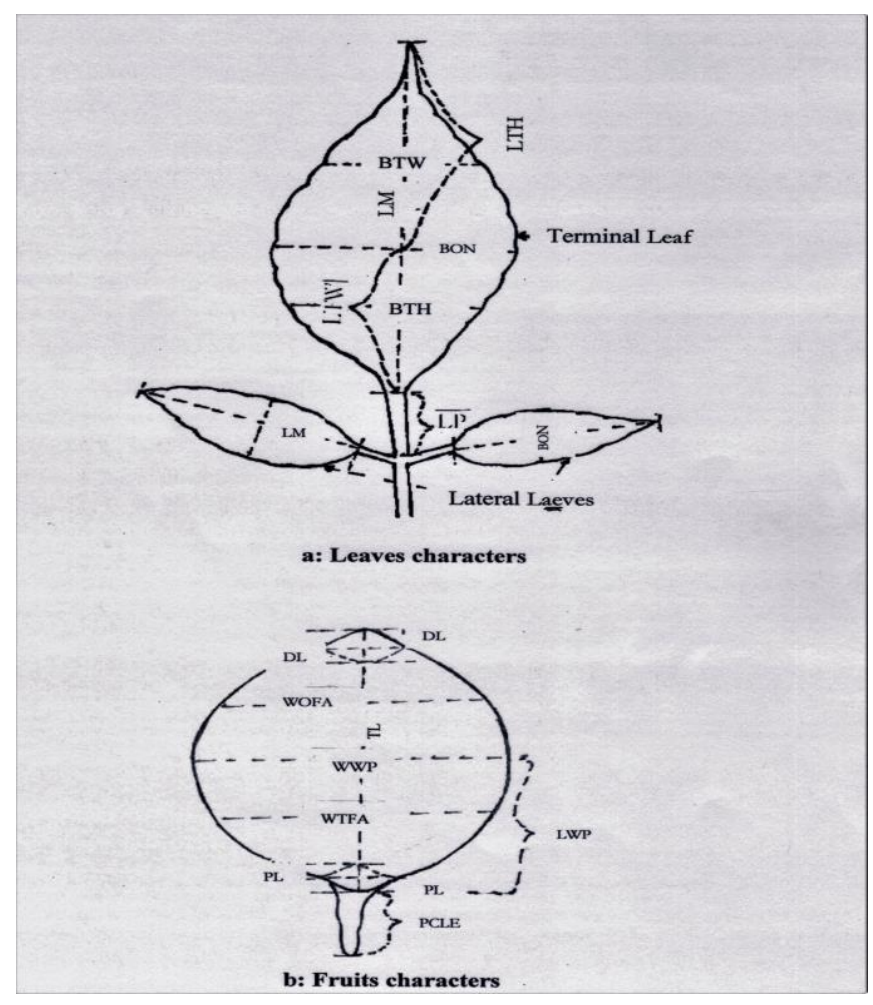

Figure 2 Morphometric characters for analysis 


\subsection{Morphometric variation}

Leaves or fruit morphological measurements were used to estimate the morphometric variation and pattern of variation of $A$. marmelos for Western Terai. They are characteristics relatively easy to measure. The fruit characteristics have a reasonably high heritability.

Table 1: The term used for the morphometric characteristics studies (Sources: Researcher, [21], [22]).

\begin{tabular}{|c|c|c|}
\hline Abbreviation & Variables & Unit \\
\hline \multicolumn{3}{|c|}{ Leaves characters } \\
\hline LM & Length of Lamina & $\mathrm{cm}$ \\
\hline LTH & Length of Lamina from apex down to the widest point & $\mathrm{cm}$ \\
\hline LTW & Length of Lamina from base up to the widest point & $\mathrm{cm}$ \\
\hline LP & Length of terminal leaflet petiole & $\mathrm{cm}$ \\
\hline BON & Maximum width of Lamina & $\mathrm{cm}$ \\
\hline BTW & Width at $1 / 3$ from apex & $\mathrm{Cm}$ \\
\hline BTH & Width at $2 / 3$ from apex & $\mathrm{Cm}$ \\
\hline Breest & $\begin{array}{l}\text { Position of the widest point in proportion to the middle point of } \\
\text { the lamina, (LM/2)-LTH) }+2\end{array}$ & $\mathrm{Cm}$ \\
\hline $\mathrm{B}$ & Width at $1 / 3$ in proportion to width at $2 / 3$, BTW-BTH & \\
\hline LB & Shape of lamina: LM/BON & \\
\hline LLP & Length of lamina compared to length of petiole: LM/LP & \\
\hline Bobtw & Shape of upper part of lamina: BON/BTW & \\
\hline Bobth & Shape of lower part of lamina: BON/BTH & \\
\hline Pet & Length of leaves petiole & $\mathrm{Cm}$ \\
\hline RatL & $\begin{array}{l}\text { Length of lamina compared to terminal leaf and the lateral } \\
\text { leaves along length: Length of terminal leaf/length of lateral } \\
\text { leaves. }\end{array}$ & \\
\hline RatB & $\begin{array}{l}\text { Length of lamina compared to terminal leaf and the lateral } \\
\text { leaves along breadth: Length of terminal leaf/length of lateral } \\
\text { leaves. }\end{array}$ & \\
\hline \multicolumn{3}{|l|}{ Fruits characters } \\
\hline PL & Pedicel length & $\mathrm{cm}$ \\
\hline PCLE & Peduncle length & $\mathrm{cm}$ \\
\hline DL & Disc level & $\mathrm{cm}$ \\
\hline LWP & Length to widest point & $\mathrm{cm}$ \\
\hline $\mathrm{TL}$ & Total length of fruit & $\mathrm{cm}$ \\
\hline WWP & Width at widest point & $\mathrm{cm}$ \\
\hline WOFA & Width at $1 / 3$ from apex & $\mathrm{cm}$ \\
\hline WTFA & Width at $2 / 3$ from apex & $\mathrm{cm}$ \\
\hline $\mathrm{SF}$ & Shape of fruit: TL/WWP & \\
\hline SUF & Shape of upper part of fruit: TL/ $1 / 3^{\text {rd }}$ & \\
\hline SLF & Shape of lower part of fruit: $T L / 2 / 3^{\text {rd }}$ & \\
\hline
\end{tabular}


All measurements were made on pressed and dried materials (Leaves and fruits which was sampled from field visit) and are explained on Table 1 and Figure 2. Sizes and shapes are defined as follows: i) the single measurement of a distance from one given point to another is size, ii) the shape is represented by ratios of size measurements, iii) when addition/substratum in size, the resulting values are considered as a size dominated shape variable, not always representing shape.

Averages were calculated for all variables for each specimen. Specimens were sorted according to geographical distance (longitude) between the sampled individuals. The data set includes 80 specimens spread over 16 longitude gradients. Measurement of leaves and fruits for a more detailed description, and abbreviation, see the text in Table 1 . The terms used for the morphometric characteristics study are given in Table 1.

\subsection{Numerical and statistical analysis}

The data recorded were first coded, categorized and fed for processing and analysis using MS Excel and SPSS (Statistical Package for Social Sciences) 12.0 computer software.

Twenty seven characteristics were evaluated. The data profile of morphometric characters among different populations were summarized using the maximum, minimum, mean, standard deviation, skewness and kurtosis. Each of the morphometric characters measured were linearly regressed and plotted against the longitude of each locality for testing the hypothesis. A comparison was made of the levels of variability among populations, using the coefficient of variation for the 27 variables with a randomized block design.

One way ANOVA with general linear method was performed to test for significant differences among populations in each of the 27 variables. The analysis of the pattern of discontinuity of the total variation was carried out i.e. a) cluster analysis for pattern of variation among all population were performed using the matrix of average population values based on the populations matrix of means. The elements of the matrix were standardized. The matrix was constructed using the square of the Euclidean distance as indicators of similarity. The groups were then represented in a dendrogram, b) Principal Component Analysis (PCA) was performed and the first four principal components were obtained. Correlation between the morphometric characters were taken into account.

\section{Result}

\subsection{Morphometric variation along longitudinal gradient}

Most of the characters measured in the 16 populations occurring along the East-West gradient were not significantly associated with longitude (Figure 3 with Appendix 1, 2 and Table 2). Except few are i.e. length of lamina (from base to apex- LM, from base up to the widest point- LTW), LTH, shape of fruit (SF, SUF, SLF), WOFA, WTFA and ratio between lateral and terminal leaves (RatL and RatB).

Although the present study area is rather small, the longitudinal gradient represents considerable environmental change, and a large variation in morphological characters is found (Figure 1). 
International Journal of Frontiers in Life Science Research, 2021, 01(01), 001-017

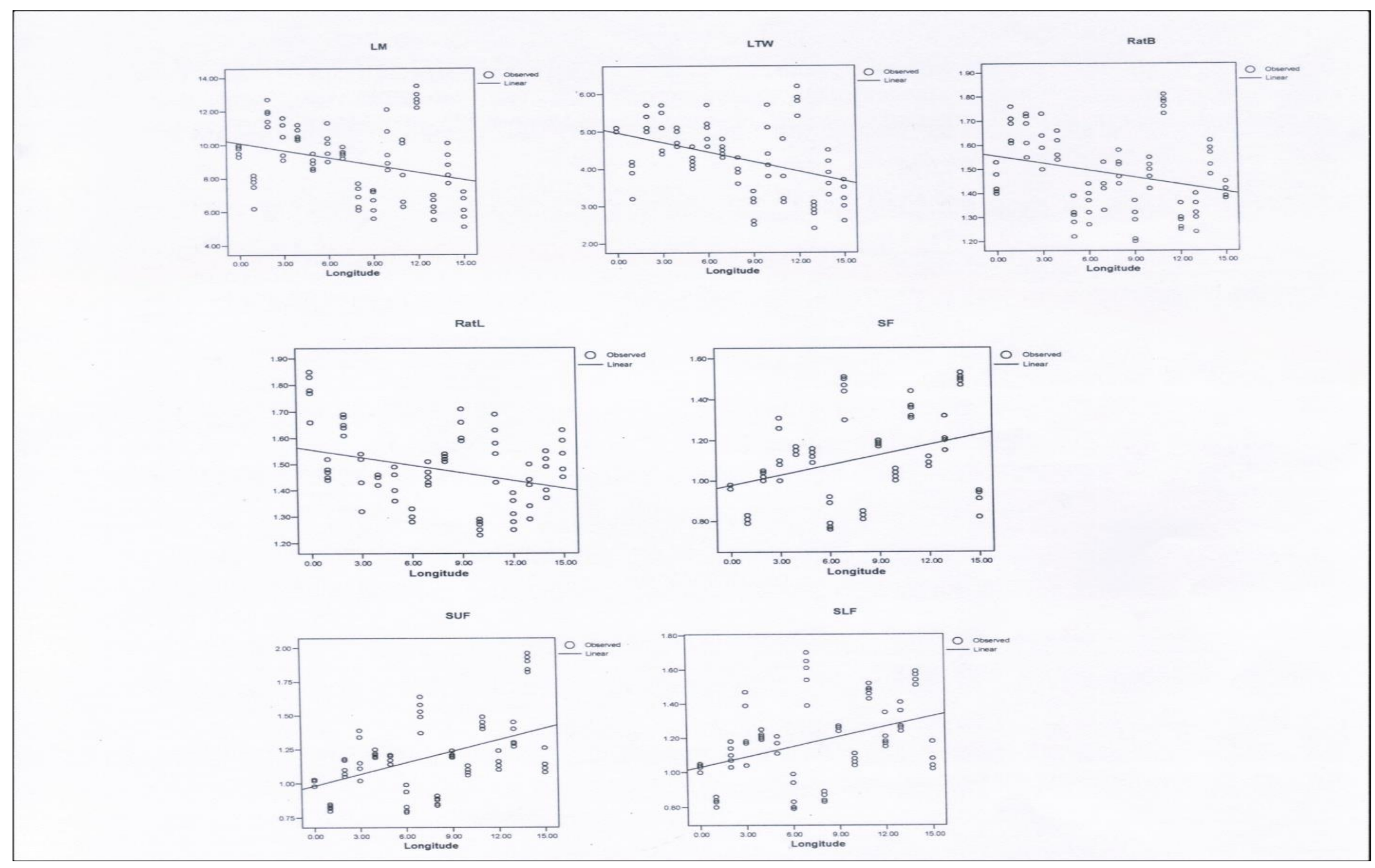

Figure 3 Longitudinal gradient of the different populations. 
Table 2 Linear regression coefficient

\begin{tabular}{|c|c|c|c|c|}
\hline SN & Character & R2 & $\mathbf{F}$ & $\mathbf{P}$ \\
\hline 1 & LM & 0.10710 & 9.3556 & $0.0030^{*}$ \\
\hline 2 & LTH & 0.5096 & 4.18857 & $0.0441^{*}$ \\
\hline 3 & LTW & 0.18683 & 17.92124 & $0.0001^{*}$ \\
\hline 4 & LP & 0.03424 & 2.76534 & 0.1003 \\
\hline 5 & BON & 0.01891 & 1.50344 & 0.2238 \\
\hline 6 & BTW & 0.0205 & 1.63263 & 0.2051 \\
\hline 7 & BTH & 0.00788 & 0.6198 & 0.4335 \\
\hline 8 & Breest & 0.03181 & 2.56303 & 0.1134 \\
\hline 9 & B & 0.03809 & 3.08907 & 0.0827 \\
\hline 10 & LB & 0.0065 & 0.50992 & 0.4773 \\
\hline 11 & LLP & 0.04556 & 3.72348 & 0.0573 \\
\hline 12 & Bobtw & 0.00205 & 0.15995 & 0.6903 \\
\hline 13 & Bobth & 0.04486 & 3.66328 & 0.0593 \\
\hline 14 & Pet & 0.00031 & 0.02422 & 0.8762 \\
\hline 15 & RatL & 0.10405 & 9.0588 & $0.0035^{*}$ \\
\hline 16 & RatB & 0.08391 & 7.14442 & $0.0092 *$ \\
\hline 17 & PL & 0.00008 & 0.00625 & 0.9372 \\
\hline 18 & PCLE & 0.00055 & 0.04299 & 0.8363 \\
\hline 19 & DL & 0.00036 & 0.02771 & 0.8682 \\
\hline 20 & LWP & 0.033 & 2.66176 & 0.1068 \\
\hline 21 & $\mathrm{TL}$ & 0.0073 & 0.57391 & 0.451 \\
\hline 22 & WWP & 0.03319 & 2.67733 & 0.1058 \\
\hline 23 & WOFA & 0.07232 & 6.081 & $0.0159 *$ \\
\hline 24 & WTFA & 0.05013 & 4.11692 & $0.0459 *$ \\
\hline 25 & SF & 0.13477 & 12.14924 & $0.0008^{*}$ \\
\hline 26 & SUF & 0.23851 & 24.43097 & $0.0000^{*}$ \\
\hline 27 & SLF & 0.15815 & 14.65328 & $0.0003^{*}$ \\
\hline
\end{tabular}

\subsection{Identification of any statistical differences in the profiles of variability}

Descriptive statistics analysis of each character at different hierarchical levels for each morphological variable tabulated which shows the mean (centre of distribution of samples) of each character, their variance, standard deviation (spread of the distribution), median, minimum and maximum, kurtosis and skewness in Figure 4. Table 3 contains the overall data on morphological attributes of $A$. marmelos from all populations with their coefficient of variation in percentage also. For each variable there is the 'minimum' (the smallest value) and the 'maximum' (the largest value) in the Table 3 , Figure 4 and Appendix 3 which give an indication of variation present in the populations.

Most of the traits were positively skewed except LTW, Pet and LP, which were negatively skewed. Summary information for continuous numeric data was displayed in a histogram. From the histogram (Figure 4 and Appendix 3) BON, BTW, 
BTH, LB, Bobtw, Bobth, DL and SUF differs significantly from a normal, symmetric distribution otherwise; all other remaining characters are in a normal symmetric distribution. The peak of the normal curve is the mean value.

\subsection{Evaluation of determining morphometric character for variation}

The coefficient of variation seen that DL had the highest (6.08), while RatL the lowest (0.095). This indicated that DL had more diversity and was more scattered in terms of distribution of the mean, similarly of PL and B. Therefore, DL, PL and B were the determining characters of morphometric for variation.
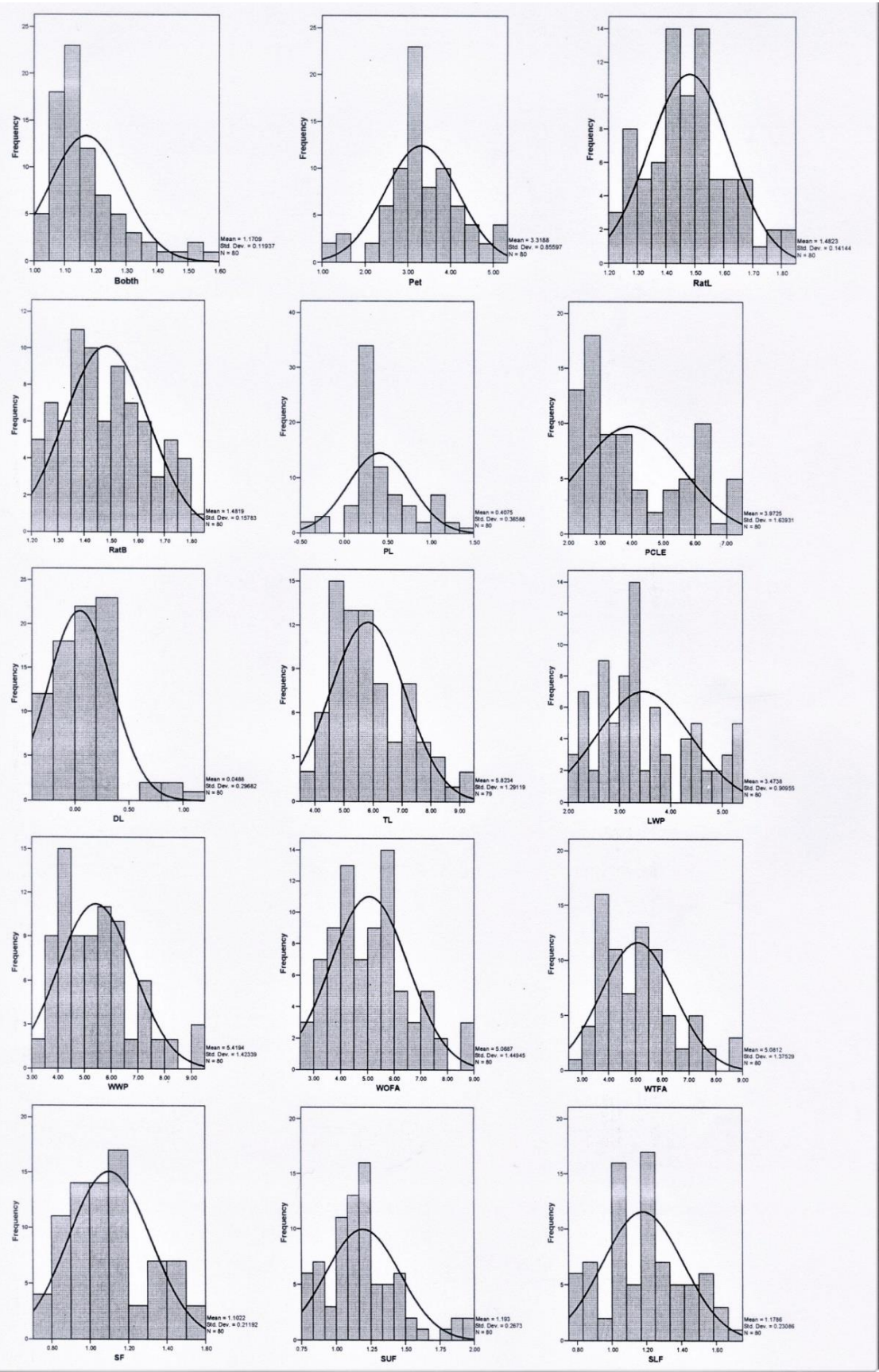

Figure 4 Histogram of different variables. 
Table 3 For descriptive analysis Abbreviations for characters are given in Table 1.

\begin{tabular}{|c|c|c|c|c|c|c|c|c|}
\hline Traits & Minimum & Maximum & Mean & Std. Deviation & Variance & Skewness & Kurtosis & CV \% \\
\hline LM & 5.10 & 13.50 & 9.0238 & 2.07079 & 4.288 & 0.063 & -0.808 & 22.95 \\
\hline LTH & 2.20 & 7.30 & 4.6900 & 1.23171 & 1.517 & 0.120 & -0.666 & 26.26 \\
\hline LTW & 2.40 & 6.20 & 4.3250 & 0.92675 & 0.859 & -0.179 & -0.748 & 21.43 \\
\hline LP & 0.30 & 2.60 & 1.4737 & 0.59209 & 0.351 & -0.052 & -0.968 & 40.18 \\
\hline BON & 2.60 & 9.50 & 4.7912 & 1.45352 & 2.113 & 1.394 & 2.551 & 30.34 \\
\hline BTW & 1.70 & 8.70 & 3.9750 & 1.45980 & 2.131 & 1.348 & 2.830 & 36.72 \\
\hline BTH & 2.20 & 8.40 & 4.1400 & 1.35839 & 1.845 & 1.266 & 1.762 & 32.81 \\
\hline Breest & 1.10 & 2.85 & 1.8219 & 0.34078 & 0.116 & 0.769 & 0.853 & 18.7 \\
\hline B & 0.00 & 2.20 & 0.8413 & 0.48723 & 0.237 & 0.780 & 0.889 & 57.91 \\
\hline LB & 1.21 & 3.57 & 1.9523 & 0.40055 & 0.160 & 1.024 & 2.237 & 20.52 \\
\hline LLP & 1.12 & 5.81 & 2.9061 & 0.97432 & 0.949 & 0.717 & 0.670 & 33.53 \\
\hline Bobtw & 1.02 & 3.67 & 1.2676 & 0.30492 & 0.093 & 6.423 & 49.724 & 24.05 \\
\hline Bobth & 1.00 & 1.56 & 1.1709 & 0.11937 & 0.014 & 1.484 & 2.260 & 10.2 \\
\hline Pet & 1.10 & 5.30 & 3.3188 & 0.85597 & 0.733 & -0.033 & 0.594 & 25.79 \\
\hline RatL & 1.23 & 1.85 & 1.4823 & 0.14144 & 0.020 & 0.386 & -0.136 & 9.54 \\
\hline RatB & 1.20 & 1.81 & 1.4819 & 0.15783 & 0.025 & 0.239 & -0.812 & 10.65 \\
\hline PL & -0.40 & 1.40 & 0.4075 & 0.36588 & 0.134 & 0.486 & 0.555 & 89.79 \\
\hline PCLE & 2.00 & 7.50 & 3.9725 & 1.63931 & 2.687 & 0.643 & -0.953 & 41.27 \\
\hline DL & -0.40 & 1.10 & 0.0488 & 0.29682 & 0.088 & 1.091 & 1.959 & 608.24 \\
\hline LWP & 2.00 & 5.40 & 3.4738 & 0.90955 & 0.827 & 0.546 & -0.692 & 26.18 \\
\hline $\mathrm{TL}$ & 3.90 & 9.10 & 5.8169 & 1.28432 & 1.649 & 0.697 & -0.200 & 22.08 \\
\hline WWP & 3.10 & 9.30 & 5.4194 & 1.42339 & 2.026 & 0.782 & 0.146 & 26.26 \\
\hline WOFA & 2.80 & 8.90 & 5.0687 & 1.44945 & 2.101 & 0.619 & -0.087 & 28.59 \\
\hline WTFA & 2.80 & 8.90 & 5.0812 & 1.37529 & 1.891 & 0.825 & 0.276 & 27.07 \\
\hline SF & 0.76 & 1.53 & 1.1023 & 0.21192 & 0.045 & 0.361 & -0.657 & 19.22 \\
\hline SUF & 0.79 & 1.96 & 1.1930 & 0.26730 & 0.071 & 0.951 & 1.055 & 22.4 \\
\hline SLF & 0.79 & 1.70 & 1.1786 & 0.23086 & 0.053 & 0.255 & -0.618 & 19.59 \\
\hline
\end{tabular}

\subsection{Analysis of variation within and between populations in the morphometric characters}

The nested ANOVA Analysis of Variance (One way) showed differences in all morphological parameters in the different populations. These differences were found within and among populations in Appendix 4. The purpose of the analysis was to find out if there were significant differences in leaves and fruits characters between the populations.

Significant differences among 26 of 27 morphological characters except variance Bobtw in A. marmelos were observed. It is clear from the results of that there are substantial variations between populations, because of the consistent and significant differences in their morphological characters. This could perhaps, be due to the populations' long-term response to different environmental conditions or by genetics. 


\subsection{Pattern of variation between populations}

Dendrogram produced by hierarchical cluster analysis of observations showed the pattern of variation of individual plant among population. The analysis showed 2 cluster plants of cluster number 7 and showed very high similarity of morphological traits. Each cluster indicates the presence of similar characters between individual plants. This indicates that the dendrogram produced by cluster analysis depicts a close genetic relationship among populations with no obvious grouping of populations with respect to taxonomic identity.

Based on morphological data by using the tool SPSS a dendrogram of the various populations was constructed. The cluster analysis (Figure 5) separated the accessions collected from 16 different populations into two major groups. Among the two major clusters, the accessions belonging to the upper cluster (UC) were collected from Shankharpur (11), Daiji (16), Devariya (36), Krishnapur 1 (21), Krishnapur 2 (26), Motipur (56), Vajni (51), Thakurdwara (61) and Khata 2 (71) while accessions belonging to the lower cluster (LC) were collected from Ghadariya (41), Ghodagodhi (46), Khata 1 (66), Malakheti (31), Belwa (76), Shuklaphanta 2 (6) and Shuklaphanta1 (1) respectively.

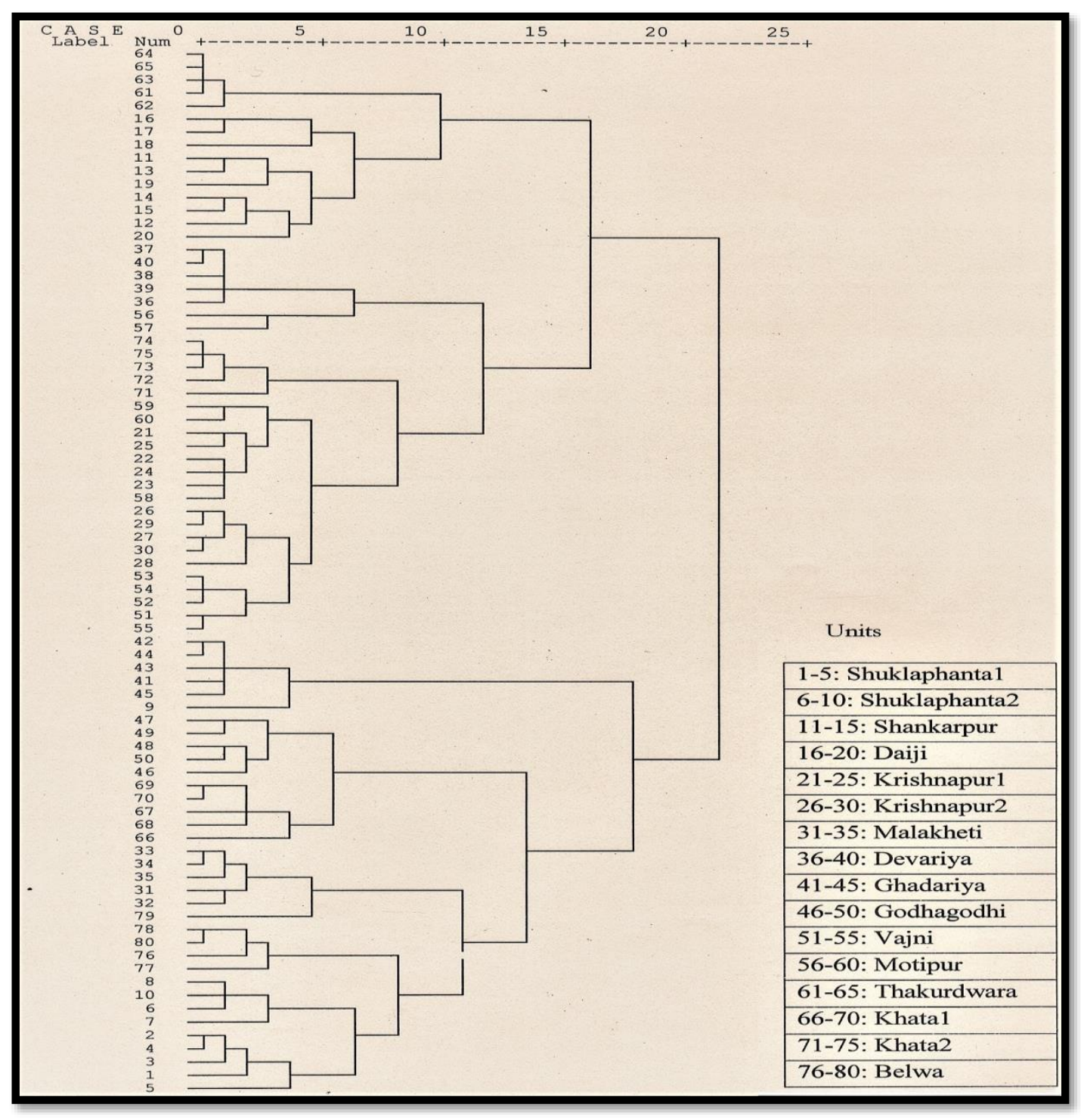

Figure 5 Cluster analysis between and within populations 
Table 4 Similarity and dissimilarity of individual plant formed from cluster analysis

\begin{tabular}{|c|c|c|}
\hline Cluster & \multicolumn{2}{|c|}{ Groups } \\
\hline Main Group I & $61,11,16,36,71,21,56,26,51$ & $41,46,66,31,76,6,1$ \\
\hline Within main group II & 61 & 41 \\
\hline III & 11,16 & 31 \\
\hline IV & 36 & 76 \\
\hline V & 71 & 6,1 \\
\hline VI & 21,56 & 46,66 \\
\hline VII & 26,21 & \\
\hline
\end{tabular}

The upper sub-cluster 1 (USC1) had collected from Shankarpur, Daiji and Thakurdwara sites; while the upper subcluster 2 (USC2) comprises collection from Krishnapur 1, Krishnapur 2, Devariya, Vajni, Motipur and Khata 2 sites. All accessions of USC1 were further sub-grouped into two major groups containing a solitary Thakurdwara site in the upper and Shankarpur, Daiji sites in the lower trunks. The lower trunks had two accessions, which are closely related (Daiji, Shankarpur) and a separate accession from Shankarpur site. The lower sub-cluster (USC2) had 2 sub-groups upper trunk Devariya and few of Motipur and lower trunk Khata 2, Krishnapur 1, Krishnapur 2 and Vajni sites. The lower trunk further divided into two groups, which are a solitary upper accession Khata2 and lower accessions Krishnapur 1, Krishnapur 2, Motipur and Vajni sites. The lower accession is further divided into upper equal weight Krishnapur 1, Krishnapur 2, Motipur and lower Krishnapur 2, Vajni sites.

Accessions of the LC were divided into two major groups. The upper sub-cluster (LSC1) had a single accession Ghadariya site. The lower half of the lower sub-cluster (LSC2) possesses 6 accessions viz. Shuklaphanta 1, Shuklaphanta 2, Ghodaghodi, Khata 1, Malakheti and Belwa sites of which Ghodaghodi and Khata 1 sites have equal weight, in upper trunk and in lower trunk has a single Malakheti accession in upper position. Whereas in lower position 3 accession are (Belwa, Shuklaphanta 1, Shuklaphanta 2 sites), which are closely related (Shuklaphanta 1 and Shuklaphanta 2) and a separated accession Shuklaphanta 2 site. The dendrogram established morphometric relatedness to among different accessions.

The first four PCA axes reflect most of the morphological variation (74.386 \%), Table 4 . Axes one explains $28.107 \% 1 / 3$ times as much as the second axis (22.683\%), similarly 2 and 3 times more than axes 3 and 4 respectively, and 5, 6 and 7 times more than 5, 6 and 7 axis.

Table 5 Summary of the results from PCA of the total data set.

\begin{tabular}{|c|c|c|c|}
\hline Axes & Eigen values & \% of Variance Eigenvalues & Cumulative \% variance of morphological data \\
\hline 1 & 7.589 & 28.107 & 28.107 \\
\hline 2 & 6.124 & 22.683 & 50.791 \\
\hline 3 & 3.649 & 13.514 & 64.305 \\
\hline 4 & 2.722 & 10.081 & 74.386 \\
\hline 5 & 1.385 & 5.129 & 79.515 \\
\hline 6 & 1.344 & 4.979 & 84.494 \\
\hline 7 & 1.134 & 4.200 & 88.694 \\
\hline
\end{tabular}

Component matrix (Figure 6) shows the loading of different characters for main seven components. It can be seen that LTW, LP, BTW, Breest, B, LLP, Bobth, WWP, WOFA and WTFA made a major contribution to the first component, while LM, LTH, BON, BTH, PL, DL, SF, SUF and SLF mainly contributed to the second component. Similarly PCLE, LWP and TL contributed to the third, LB, Pet to the fourth, RatB to the fifth and Bobtw and RatL to the sixth component. 
Principal coordinate analysis explained $28.1 \%$ and $22.6 \%$ of the total phenotypic variance along the first and second axes respectively, and it identifies two separate groups, as in the cluster analysis (Figure 5). On plotting the first two axes of the principal coordinate analysis, the following graph (Figure 6) was obtained. It visually describes the direction and value of each population contributing to the variation of $A$. marmelos traits collections. It is clear that Shuklaphanta, Malakheti, Devariya, Ghadariya, Vajni, Motipur and Khata 2 had high loading on PCA 1 (factor score 2 for analysis 1), while Shankarpur, Daiji, Krishnapur, Ghodagodi, Khata 1, Thakurdwara and Belwa had high loading on PCA 2 (factors score 1 for analysis1).

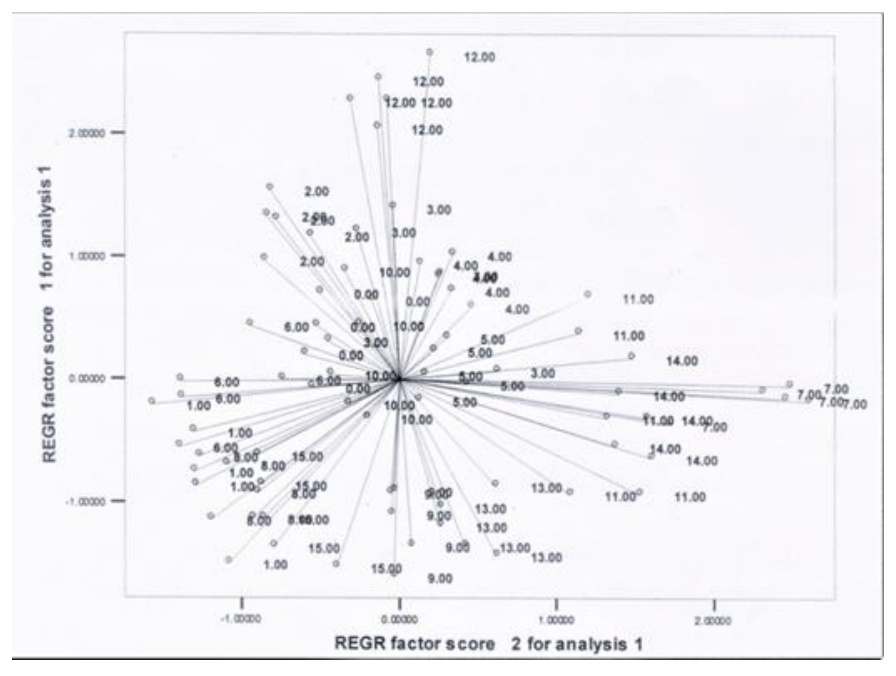

Figure 6 PCA diagram of the analyzed morphological characters for axes one and two.

\subsection{Correlation of morphometric characters}

Pearson's coefficient of correlation has been analyzed for each hierarchical traits to interpret whether the individual traits are or not significantly correlated with each other. Correlation between morphological variables is given in Appendix 5. The correlation matrix computed between different morphological characteristics, showed that out of 350 , 124 coefficient were significantly $(\mathrm{p}>0.05)$ positively correlated and 73 were negatively correlated. Hence, it is pertinent to state that most of the morphological characters were correlated linearly.

\section{Discussion}

For describing and analyzing morphometric variation different characters were used on them fruits weight, seed and pulp characteristics for describing that variation of the A. marmelos by [23] and Singh [24], but in this study, different morphometric characters of leaf and fruit i.e. size and shape were used. For determining intraspecific variation within a species, study of the morphometric variation is very important and several study were done related to subspecies or below of these hierarchical level by using of morphometric characters.

The morphometric studies on both leaf and fruit indicate that phonetic continuum exists within A. marmelos on Western Terai. The phenotype or morphotype is the product of the interaction of genotype and environment, and that any given genotype will produce different phenotypes in different environments [25].

The result in Table 2, Figure 3 and Appendix 1, 2 shows directional discrete variation in most of the morphological characters along the East-West gradient of Nepal and supported the hypothesis that species with longitudinal gradient would have not phenotypes those are more variable. However, some quadratic regressions revealed that the relationship between length of lamina (from base to apex: LM and from base up to the widest point: LTW), LTH, shape of fruit (SF, SUF, SLF), WOFA, WTFA and ratio between lateral and terminal leaves (RatL and RatB) (p<0.05). This suggests that random processes rather than natural selection, plays a dominant role in shaping these characters. When natural selection is predominant, we may expect populations in close proximity to be morphologically more similar than those far apart because the macro environments (and therefore selective force) are likely to be more similar over short than over long distances [26]. However, when genetic drift is the main mechanism, such a relationship between phenotypic similarity and geographical distance is less likely which was observed in this study. 
The discrete variation along longitudinal gradient may be the result of small geographical areas or climatic/environmental factors (rainfall, temperature, humidity) which is not uniform from East to West of the study area (Figure 1). If there is a relationship between environmental variation and phenotypic variation within species, it is reasonable to hypothesize that species that occupy a wider range of habitats (habitat generalists) will be more variable in phenotype than species that occupy a narrow range of habitat [27].

Differences in population genetic diversity arise due to feature related to the extent of distribution of the species and or population as well as the successional stage of population. Breeding system, seed dispersal and most importantly, geographical range had predictive roles in shaping the genetic structure of populations. More spread species, as well as species that are out crossed tend to have greater diversity within population. $A$. marmelos occurs in gregarious groups along river systems in water logged conditions (field visit). Population along the same water sources (river, lakes, pond, etc) have greater chances to be related and result in low genetic variation between populations because during floods the fruits (seeds) are often carried to long distance and deposited along the banks of rivers giving rise to gregarious stands. Thus, population sampling across longitudes may not give the desired diversity in A. marmelos.

In statistics, the concept of a population is an abstraction signifying theoretically large assemblage of individuals from which a particular group under consideration is a sample. Most biologist uses of the term however imply the total of organism belonging to a particular taxonomic group (or taxon) which are found in a particular place at a particular time. The population unit of outstanding significance in the study of variation is quite different being the local interbreeding group of individuals sharing a common gene pool [28].

According to [25], differences between individuals are of three main types, 'developmental', 'environmentally induced' and 'intrinsic'. In this study morphometric characters had shown variation in different populations which are collected for the study. The phenomenon of developmental variation by which the adult differs, often strikingly from the immature individual however, here in this study the variation is not of such type because the samples for the study were taken from similar age group plants i.e. mature and at same time and season. The variable in characters may be results of different climatic factors (Figure 1, b) or environmentally induced. The expression of many developmental traits depends on the environmental conditions, which defines the unique plant developmental plasticity i.e. the capacity of a genotype to express different phenotypes depending on the environment. Abiotic signal such as light, temperature, humidity, water availability or nutrient resources as well as most biotic components of the surrounding environment from pathogens to competitions are the environmental factors for affecting plant development [29]. Such types of the factors remaining in the Western Terai are in variable and causes to being of the morphometric variation in the $A$. marmelos. Phenotypic variation is due largely to phenotypic plasticity [30] although genetic differentiation can also play an important role [31].

Cluster analysis through forming of dendrogram separated different populations of the study area according to the morphometric variation. The DL, PL and B have higher of the CV \% value and the characters which are higher coefficient of variation (CV) higher will be the variability, show the most consistent and uniform value. On the different populations the characters Disc level (DL) and Pedicel length (PL) are negative and positive values. Therefore, these characteristics mainly determined such types of the dendrogram. From the dendrogram 2 main branched were found along with other seven subgroups. The groups that were together have the similar characters. The populations that are nearer to each other are not cluster together; it may be the others responsible factors beyond environmental factor. Even in the nearer populations have not similar macroclimatic environment (Figure 1, b) and is responsible for forming morphometric characters variation among these populations, also. A principal component analysis (PCA) of the populations (Figure 6, Table 4) further confirmed this. However, it is unable to separate seven subgroups as did by dendrogram. The Analysis of Variance (Appendix 4) also determined variation of the populations. The variation in the morphometric characters may be the result of the different environmental factors or by the genes having on the plant.

Size is often considerable less important than shape as it is being more affected by fluctuations in the external environment and age, and having little to do with genetic compositions [32], shape is thought to be predominantly under genetic control [33]. However, [34] had found size is an important feature of morphology and to be genetically defined in Nothofagus plant species [35]. Considering these considerations, the regression analyses reject the hypothesis (Table 2 ) as expecting the shape and size to be constant when dealing with leaf and fruit of $A$. marmelos. As a variation is usually discontinuous in the univariate statistics (Figure 3 and Appendix 1,2), groups are delimited. So, it may suggest the occurrence of variation within A. marmelos. Nine varieties of A. marmelos for cultivation referred for the farmer by yield and weight of fruits, pulp and number of seeds per fruits, rind thickness and pulp characteristics [23], [36]. Similarly, [37] describe 7 cultivar varieties of $A$. marmelos referred for cultivation by 'Krishi Vighan Kendra' Orisaa. 
Genetic drift and/or the founder effect have been implicated as a determining factor of the population genetic structures of several species [38]. Thus, even if the breeding unit within A. marmelos populations is the actual size of the population, genetic drift has probably been responsible in some part for both the low variation within populations and the extensive variation between populations. Low levels of gene flow combined with the effects of random genetic drift and local populations to selection may, cause small, geographically distant populations to diverse genetically. Morphometric diversity data are important for conservation and management of $A$. marmelos species. Because a large proportion of morphometric variation in $A$. marmelos was found to be among individuals within populations, a considerable amount of genetic variation of the species could be obtained when sampling a large number of plants from one or two populations rather than smaller collections from many different sites, and the same would be true for any conservation plan.

\section{Conclusion}

Morphometric variation of $A$. marmelos in the natural stands from the study area i.e. Western Terai Landscape Complex has been estimated. For this diversity, altogether 27 morphometric characters of leaves and fruits have been assessed in the sample plants. Uni- and multi-variate analysis supports the separation, as several characters of both leaves and fruits and revealed remarkable variation among populations. The discrete variation along longitudinal gradient was shown by linear regression of plant traits. Morphometric variation of the A. marmelos was observed along with different habitat in the study area; either it may be by the environmental or genetic factors. The plant is the most important medicinal as well as religious plant of human use. In Hindu religion, conservation of this plant is given more emphasis. Due to little knowledge of its economic importance, it has not been widely cultivated and at present, this plant is very rare crops. Even cultivation of the plant cannot preserve/conserve wild genes of the plant, it may be mutated or loss. Therefore, the plant genetic conservation is very important issue.

\section{Recommendation}

Further, multi-disciplinary research, involving botany, ecology, geography, remote sensing, GIS and computer programming as was the case for this study, to enhance habitat protection of such precious species as $A$. marmelos. Provided information can be utilized to preserve genetic resources of Nepal and for the management of internal resource, endowed to use as A. marmelos.

\section{Compliance with ethical standards}

\section{Acknowledgments}

I am indebted to WTLCP/LiBIRD/GEF-UNDP, SNV for the funding to this study. I am thankful to MFSC, Department of National Parks officials for giving permission to study in the protected areas of Western Nepal. It is acknowledged to local communities of survey districts for sharing their knowledge. I extend my grateful towards Prof. Dr. Ram Prasad Chaudhary, Dr. Abishkar Subedi, Dr. Achyut Adhikari, Dr. Bimal Raj Regmi, Pitamber Shrestha and Hari Poudyal for their continued supervision of this research. The gratitude is extending towards my friend Bikash Baral, PhD scholar for his incessant encouragement to prepare this manuscript.

\section{References}

[1] Grant, V. Plant Speciation, 2nd Edn. New York: Colombia University Press. 1981.

[2] Clausen, JD, Keck D and Heisey, WM. Experimental Studies on the Nature of Species. III. Environmental Responses of Climatic Races of Achillea. Carnegie Institutional of Washington Publication 1948; 520.

[3] Sun, B, Dilcher, DL, Beerling, DJ, Zhang, C, Yan, D, Kowalski, E. Variation in Ginkgo biloba L Leaf Characters across a Climatic Gradient in China. Proc. Natl. Acad. Sci. USA. 2003; 100:7141-7146.

[4] Small, E and Fawzy, M. Morphogeographic Variation in the Medicago monantha Complex. Canadian Journal of Botany. 1992; 70:1292-1301.

[5] Allen, GA, JA. Antos, AC Worley, TA Suttil, Hebda, RJ. Morphological and Genetic Variation in Disjunct Populations of the Valanche Lily Erythronium montanum. Canadian Journal of Botany 1996; 74:403-412.

[6] Passioura, JA, Ash, JE. Phenotypic, Genetic and Ecological Variation in the Euclyptus saligna- E. Botryoides complex. Australian Journal of Botany 1993; 41:393-412. 
[7] Sandquist, DR and Ehleringer, JR. Intraspeciefic Variation of Drought Adaptation in Brittlebush: Leaf Pubescence and Timing of Leaf Loss Vary with Rainfall. Oecologia, 1998; 113:162-169.

[8] Wilson, SD. Plasticity, Morphology and Distribution in 12 Lakeshore Plants. Oikos. 1991; 62:292-298.

[9] Van Tienderen, PH. Variation in a Population of Plantago lanceolata Along a Topographical Gradient. Oikos. 1992; 64:560-572.

[10] Simpson, MG 2006. Plant Systematics. Elsevier Academic Pr3ss. Canada.

[11] Mortan, J. Bael Fruit. In: Fruits of Warm Climates. (Eds. J F Morton and FL Miami). 1987; Pp 187-190.

[12] Bhattarai, KR and Ghimire, M. Cultivation and Sustainable Harvesting of Commercially Important Medicinal and Aromatic Plant of Nepal. Heritage Research and Development Forum, Nepal, 2006.

[13] Joshi, SG 2006. Medicinal Plants. Oxford \& IBH Publishing Co. Pvt. Ltd.

[14] Kunwar, RM. Non Timber Forest Product of Nepal. A Sustainable Management Approach. Centre for Biological Conservation Internationa;l Tropical Timber Organization Nepal-Japan, 2006; 423p.

[15] Manandhar, NP. Plants and People of Nepal. Timber Press, Portland, Oregon, USA. 2002.

[16] Watanable, T, Rajbhandari, KR, Malla, KJ and Yahara, S. A Hand Book of Medicinal Plants of Nepal. Non-Profit Organization Ayur Seed Life Environmental Institute (Ayurseed L.E.I), 2005.

[17] Suresh Babu, S and Madhavi, M. Green Remedies: Healing Power of Herbs. Pustak Mahal, Delhi, 2006.

[18] Ambasta, SP, K Ramchandran, K Kashyapa, Chand, R. The Useful Plants of India. Council of Science and Industrial Research, New Delhi. 1992.

[19] Mortan, J. Bael Fruit. In: Fruits of Warm Climates. (Eds. J F Morton and FL Miami). 1987; Pp 187-190.

[20] WTLCP 2006. Western Terai Landscape Complex Project. Brochure. www.wtlcp.org.np

[21] Arnesen, V. Character Variation in Rhododendron arboretum Sm. And R. Wallichi Hooker f. along an Elevation Gradient in Eastern Himalaya (Nepal). M.Sc. Dissertation, Submitted to Botanical Institute, University of Bergen, Norway. 2000.

[22] Shaw, MJ, Potts, BM and Reid, JB. Variation within and Between Eucalyptus nitida Hook. f. and E. coccifera Hook. f. Australian Journal of Botany. 1984; 32:641-654.

[23] Teaotia et al. 1963. Indian Journal of Horticulture. 20: 210. “The Wealth of India, Raw Material Vol. I", Publication and Information Directorate, CSIR New Delhi 1985; pp 85-91.

[24] Singh, RD. Studies on the Bearing Habit and Fruit Development in Bael (A. marmelos Correa) Cultivar Mirzapuri Kagzi. Progressive Horticulture. 1986; 18(3-4):277-284.

[25] Briggs, D and Walters, SM. Plant Variation and Evolution (3 ed.). Cambridge University Press, New York. 1997; 512 p.

[26] Endler, JA. Geographical Variation, Speciation and Clines. Princeton University Press, New Jersey. $1977 ; 246$ p.

[27] Sultan. SE. Phenotypic Plasticity for Fitness Components in Polygonum species of Contrasting Ecological Bredth. Ecology. 2001; 82:328-343.

[28] Michaelis, A and Green, MM. Rev. Ed. Glossasry of Genetics and Cytogenetics. 4th ed: Springer-Verlag, Berlin; New York. 1976, p. 509-533.

[29] Tonor, SJ, Alonso-Blanco, C and Koornneeff, M. Gene Function Beyond the Single Trait: Natural Variation, Gene Effects and Evolutionary Ecology in Arabidopsis thaliana Plant. Cell and Env. 2005; 28: p. 2-20.

[30] Anderson, CM and Treshow, M. A Review of Environmenatl and Genetic Factors that Effect Spartina alterniflora Loisel (Salt Marsh Cord Grass). Estuaries 1980; 3:168-176.

[31] Ghallagher, JL, Somers, GF, Grant, DM and Seliskar, DM. Persistent Differences in Two Forms of Spartina alteriflora: a Common Garden Experiment. Ecology 1988; 69:1005-1008.

[32] Jolicoeur, P And Mosimann, JE. Size and Shape Variation in the Painted Turtle. A Principal Component Analysis. Growth 1960; 24:339-354. 
[33] Gillham, MC and Claridge, MF. A Multivariate Approach to Host Plant Associated Morphological Variation in the Polyphagous Leafhopper, Alnetoidia alneti (Dahlbom). Biological Journal of the Linnean Society1994; 53(1):127151.

[34] Premoli, AC. Leaf Architecture of South American Nothofagus (Nothofagaceae) Using Traditional and New Methods in Morphometrics. Botanical Journal of the Linnean Society, 1996; 121:25-40.

[35] Atchely, WR. Some Genetic Aspects of Morphometric Variation, p. 346-363: In Felsenstein, J. (ed.). Numerical Taxonomy. Springer-Verlag, Berlin. 1983; 644: p. 346-363.

[36] Jauhari and Singh 1971-72. Indian Journal of Horticulture. 1971; 16(1): 9.

[37] Mohapatra, SC. Cultivate Bael in Dry Areas to Fight Malnutrition. Agrobios Newsletter. 2008.

[38] D.F. Penney, E.G. Zimmerman, Genic Divergence and Local Population Differentiation by Random Drift in the Pocker Goper Genus Geomys. Evolution, 30: 473-483, 1976. 